\title{
Development and analysis of vawt offgrid in ducting system
}

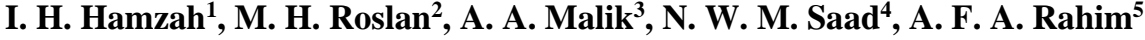 \\ Faculty of Electrical Engineering, Universiti Teknologi MARA, Cawangan Pulau Pinang, Malaysia \\ School of Engineering, Penang Skills Development Centre, Malaysia
}

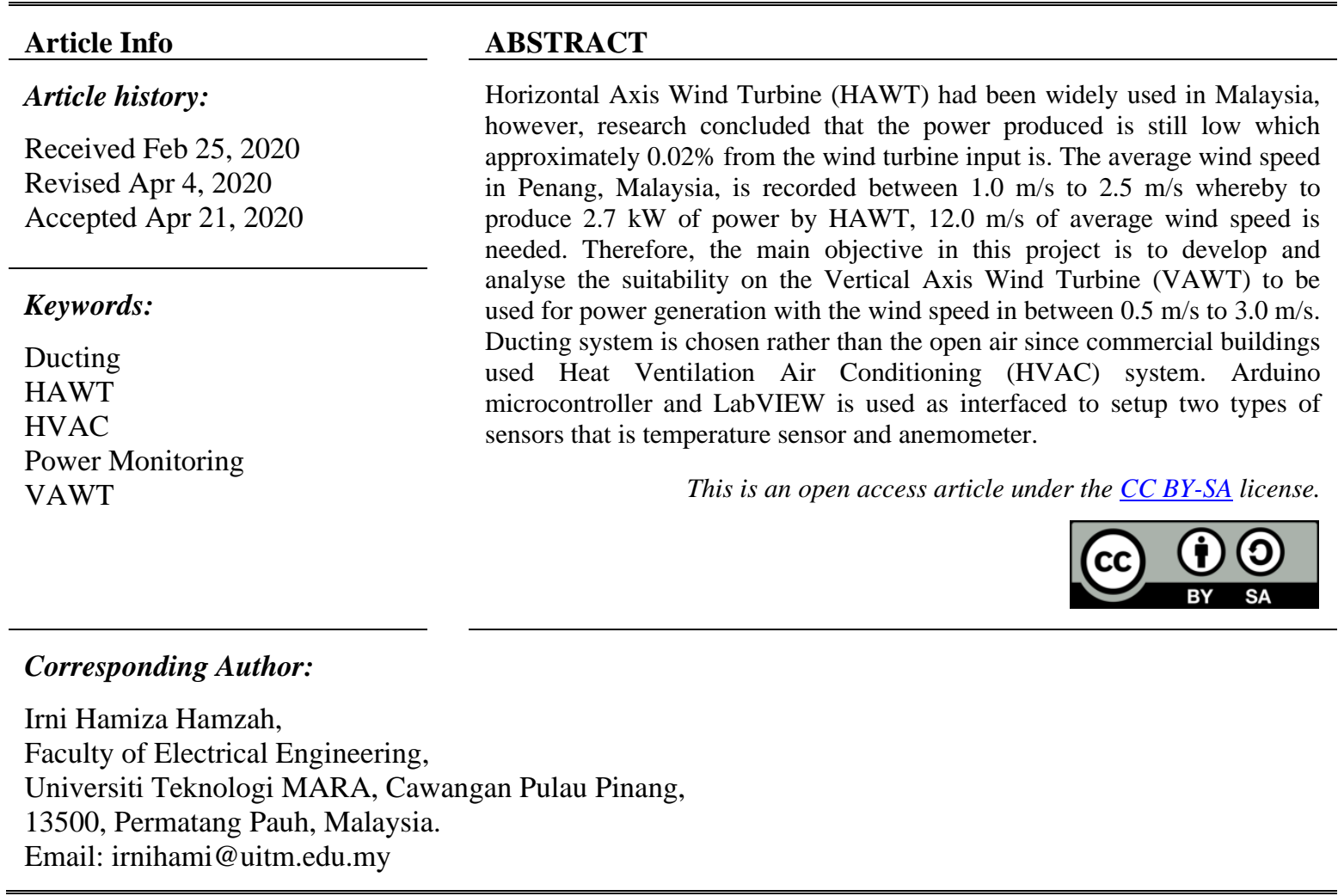

\section{INTRODUCTION}

Renewable energy accumulated from renewable sources such as daylight, wind, rain, tides, waves, and geothermal heat. Renewable energy is converting natural phenomenon into electrical energy [1]. There are many types of renewable energy around the earth such as from sun [2], wind [3], biomass [4] and biogas [5]. Renewable energy often provides power in 4 essential regions: energy generation, air and water heating/cooling, transportation, and rural (off-grid) energy services [6]. Wind power has become one of the fastest emerging renewable energy technologies for electricity generation, and the total installed capacity has reached $487 \mathrm{GW}$ (about 4\% of the global electricity) by the end of 2016 [7]. In Malaysia, horizontal axis wind turbine is widely implemented in Malaysia but Sustainable Energy Development Authority (SEDA) still not declare wind as renewable energy [8]. Wind energy is still not practical because based on previous study by A.R.N. Razliana in 2012 [9], the power harvested using wind energy is around in 50W which is low and the power produced was not constant in time. Then, from previous research by J. Ahmadian et al. [10] which was carried out in Kuala Terengganu Horizontal Axis Wind Turbine (HAWT) of the input power $2 \mathrm{MW}$ only able to produce $3.5 \mathrm{~kW}$ output power. Hence, this proved that HAWT is not practical and the best solution to be implemented in Malaysia. Therefore, further study needs to be done to find the best method to be implemented in Malaysia.

Wind energy is of the best renewable energy due to cost reduction of wind power generation, improvement of the used technology and equipment reliability [11]. Two types of the most popular wind turbines are Fixed Speed Wind Turbine (FSWT) and Variable Speed Wind Turbine (VSWT) [12]. Basically, FSWT in wind turbine consists of 2 types that are Horizontal Axis Wind Turbine (HAWT) and Vertical Axis 
Wind Turbine (VAWT) [13]. Vertical Axis Wind Turbine (VAWT) is operating in perpendicular to the directions of wind and ground [14]. VAWT is able of accepting wind from any direction. A main difference between HAWT and VAWT is VAWT does not need the Yaw system to capture the wind [15]. Vertical axis of rotation will be focused in this research. Vertical axis wind turbine is chosen in this project as the methodology to be investigated due to its application to be implemented in Heat Ventilation Air Conditioning (HVAC) ducting system which is installed inside the buildings. Shah et. al. [16] in his research claimed that VAWT is relatively simple to implement in urban areas on ground or/and building-roofs.

Heat Ventilation Air Conditioning (HVAC) ducting system is air distribution in the building such as mall, hotel and etc. The function of this system is to control the temperature and ventilation [17]. Wind turbine is applying inside the HVAC ducting system and power management system, from air pressure in the ducting system indirectly can be harvested and store energy [18]. HVAC is chosen due to the turbines work best in environments with strong and consistent winds [19]. The concept is same that air flow crosses the earth surface will have produced kinetic and convert to electrical energy [20]. HVAC system in commercialize buildings can operate more than 12 hours and 24 hours for shopping complex and hotel respectively [21]. The pressure inside the HVAC system is come from blowers by the ducting system [22]. Meanwhile, in domestic building the energy that is harvested in through ducting system able to produce the constant power [23]. This is because the blower can generate air flow through the ducting system continuously. Air pressure in ducting system depend on the types of the facility, normally produce between $1000 \mathrm{cfm}-15000 \mathrm{cfm}$. The benefits using ducting system is it can produce the power consistently and in a longer time period. Therefore, the application on the existing equipment in building, which is HVAC ducting system is proposed in this project by application of VAWT as a new renewable energy harvesting method. The performance on the output voltage will be measured by oscilloscope at the three phase generator located near to the VAWT.

\section{RESEARCH METHOD}

Four wind turbines are used in this project in which each wind turbine is 500W located in the ducting system. Arduino Uno is used as the interface with Anemometer and Temperature sensor. Data on speed air and temperature were collected and saved to the LabView. Power supply to the Arduino is $12 \mathrm{~V}$. Each of Arduino is setting in different parameters. Figure 1 shows the wind turbine off- grid system.

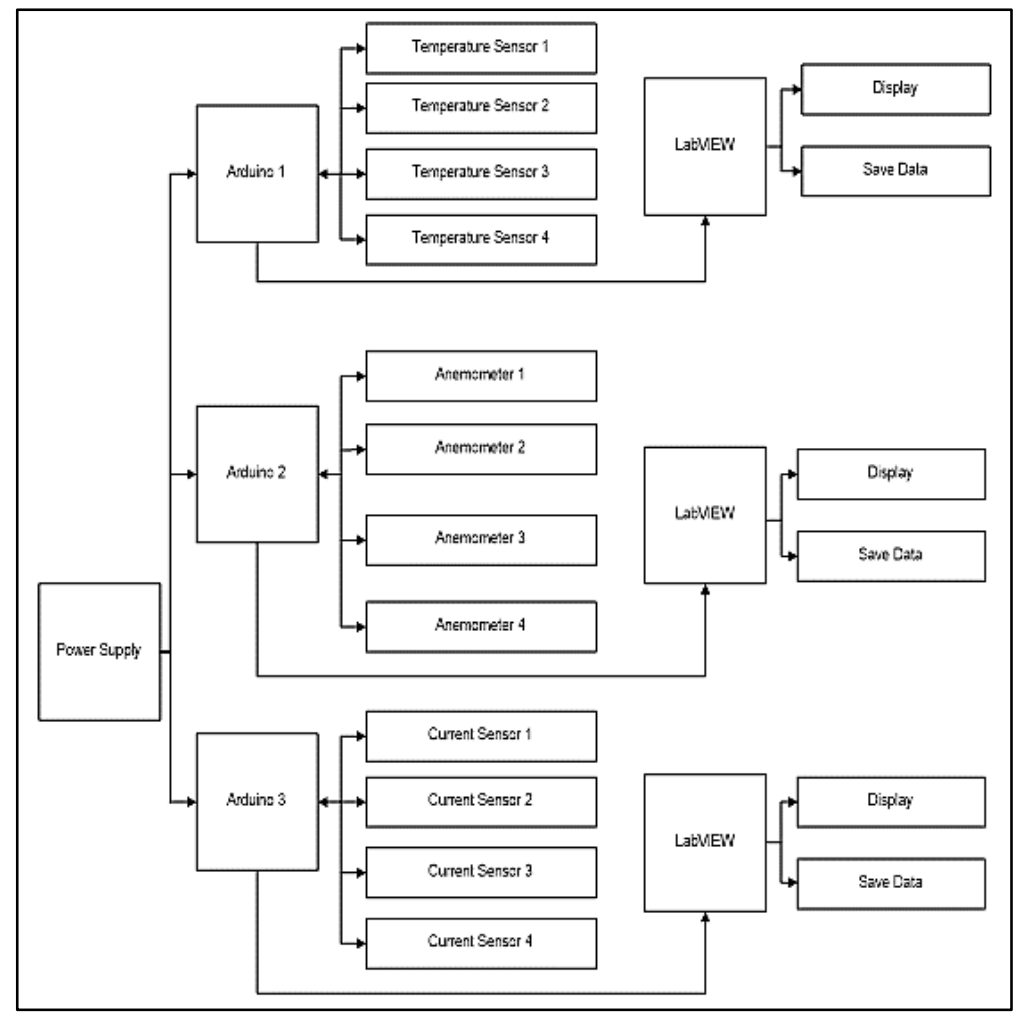

Figure 1. Block diagram of control and monitoring system 
Arduino received the output sensor in analog signal form. Whenever the sensor detects any change on the parameter, the signal will be sent to the Arduino. Temperature sensor used is LM35 as shown in Figure 2, anemometer used is shown in Figure 3 and current sensor used is ACS758 as shown in Figure 4. Arduino consists of ADC converter that convert the signal from analog to digital since the sensor sent the signal in analog form. LabView does not consists ADC converter because it can locate the output voltage in the sensor mechanically. LabView will received the output voltage and immediately sent to the LabView Makerhub.

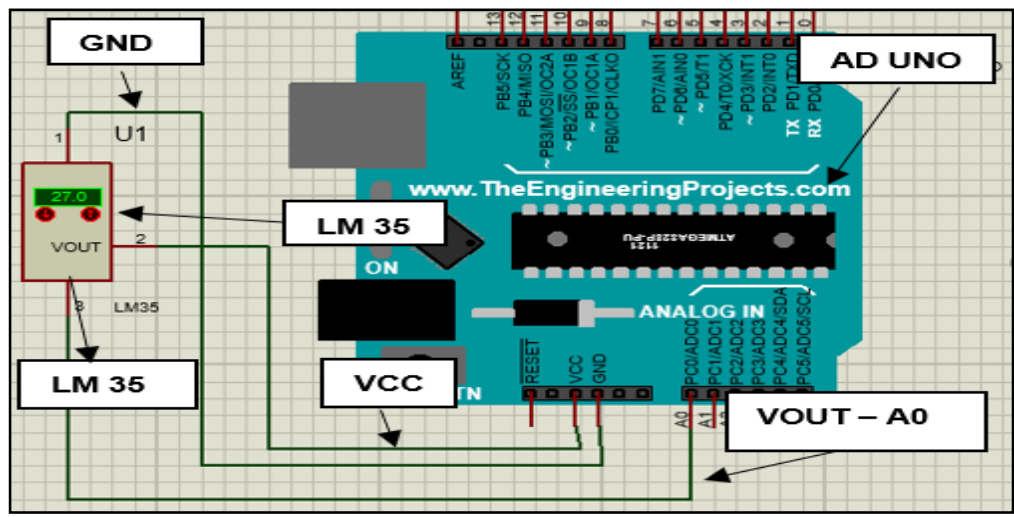

Figure 2. LM35 interface with the Arduino

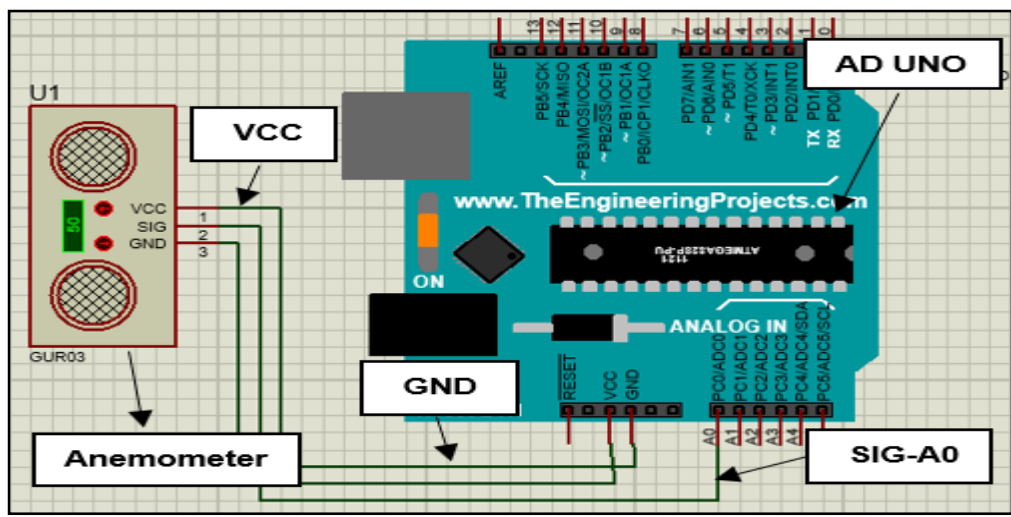

Figure 3. Anemometer interface with Arduino

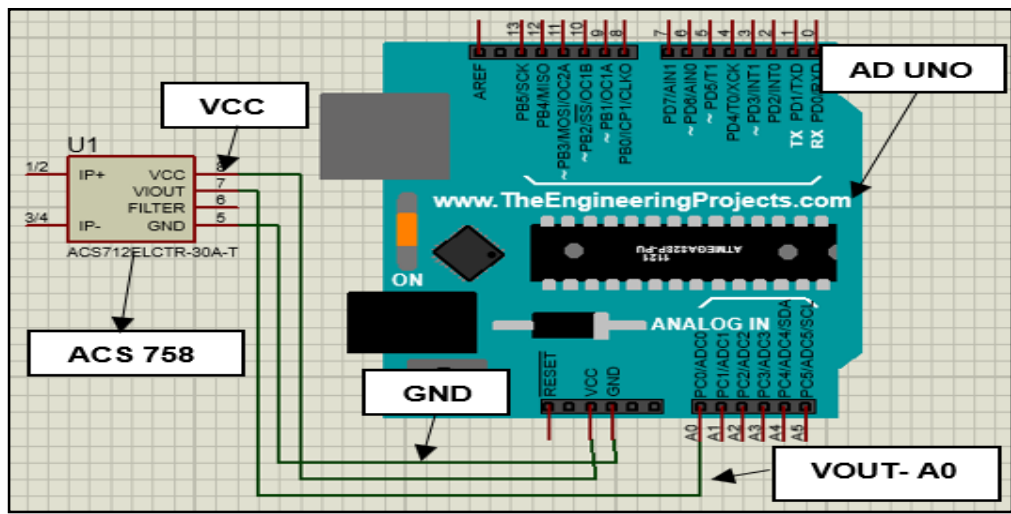

Figure 4. ACS 758 interface with Arduino 


\section{RESULTS AND DISCUSSION}

Figure 5 shows the graph for air velocity input speed at the air blower versus the air velocity ouput at the wind turbine. The anemometer sensor has been located at one of the VAWT as shown in Figure 6.

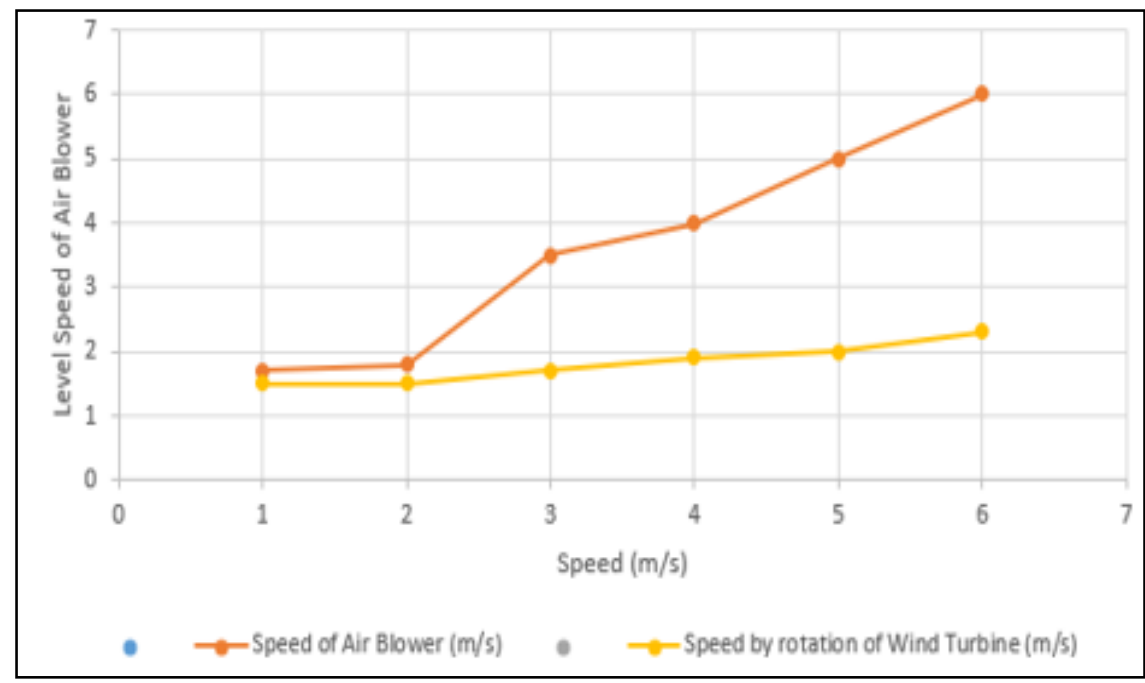

Figure 5. Air velocity output on air blower and wind turbine

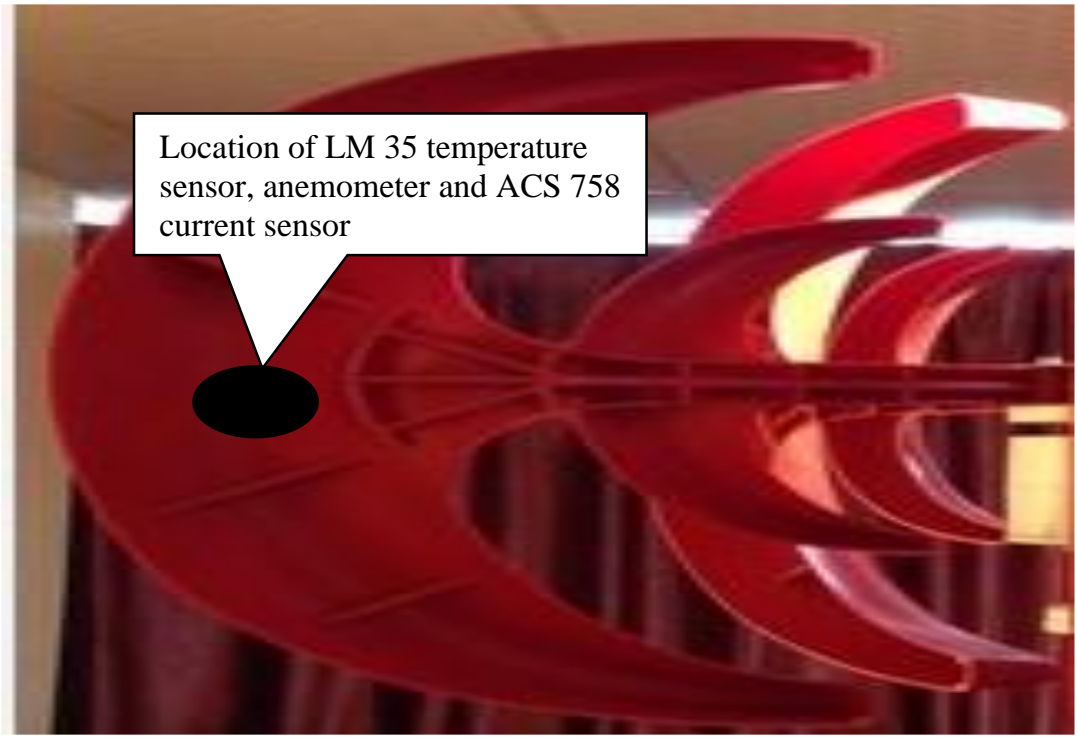

Figure 6. Location of sensors at the VAWT blade

Figure 7 reflects the value on the temperature inside the ducting system from minute 1 until minute 10. It shows that the value on the temperature inside the ducting system is not constant due to the friction produced between the air pressure and the wind turbine. It is important to monitor the temperature inside the ducting system since it can influence the stability on the electronics part of generator, cable wiring, converter etc. 


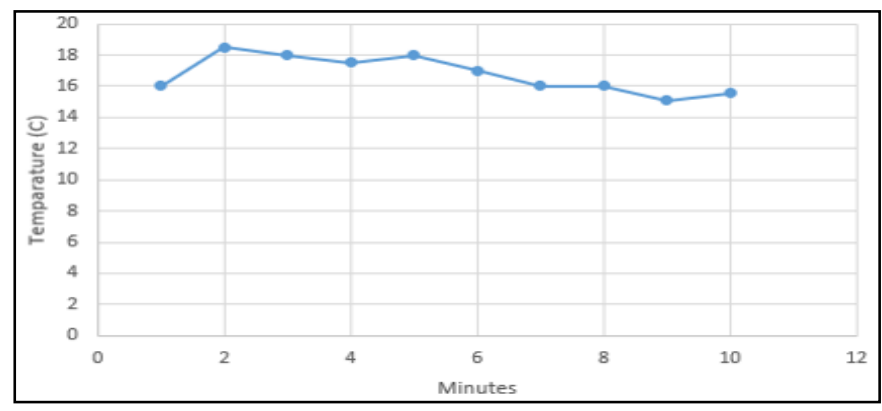

Figure 7. Temperature inside the ducting system

Figure 8 indicates the output voltage produced by wind turbine at each level of air velocity input. The measurement had been done at three phase generator located near the VAWT indicated by Live 1 (L1), Live 2(L2) and Live 3 (L3) as shown in Figure 9. These experiments are conducted based on the research carried out by Leow et. al. that wind speed does have the influence on the performance of photovoltaic panel [24]. Figure 8 shows that at level 3 in which the air velocity input of air blower is $3.5 \mathrm{~m} / \mathrm{s}$, the maximum output voltage produced for all L1, L2 and L3. This indicates that the output voltage produced does not necessarily maximum when the air velocity is at maximum speed. This is believed due to cut-out speed phenomena in which as the speed increases above the rate output wind speed, the forces on the turbine structure continue to rise and, at some point, there is a risk of damage to the rotor. As a result, a braking system is employed to bring the rotor to a standstill [25]. In this project, the cut-out speed occurs at $3.5 \mathrm{~m} / \mathrm{s}$.

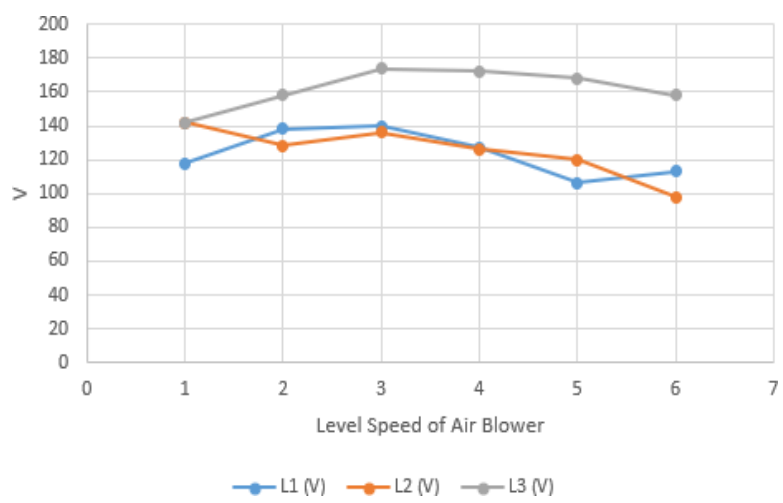

Figure 8. Output voltage produced by wind turbine at each level speed of air blower For Live 1, Live 2 and Live 3

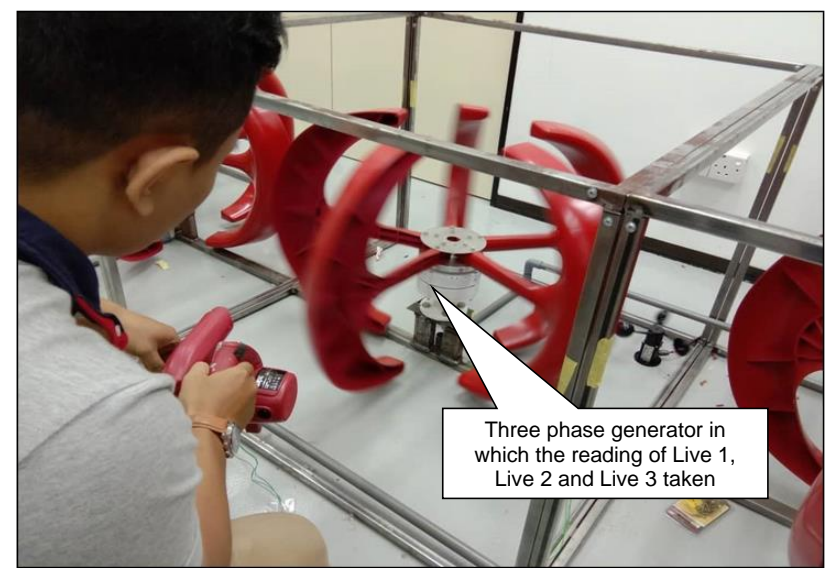

Figure 9. Location of Three Phase Generator VAWT 


\section{CONCLUSION}

This paper presents the development on four wind turbines in which each wind turbine is $500 \mathrm{~W}$ of power and located in the ducting system. Analysis on data taken which is temperature, air velocity and voltage have been done using VAWT located inside the ducting system. It was observed that minimum air velocity speed needed which was only $1.8 \mathrm{~m} / \mathrm{s}$ to generate an average voltage of $133 \mathrm{~V}$. With this minimum air velocity input speed air blower of $1.8 \mathrm{~m} / \mathrm{s}$, the air velocity ouput at the wind turbine will be $1.7 \mathrm{~m} / \mathrm{s}$. The average temperature in ducting system in 10 minutes is $16.73^{\circ} \mathrm{C}$.

\section{ACKNOWLEDGEMENTS}

This work is sponsored by the Ministry of Higher Education (MOHE) fund from Fundamental Research Grant Scheme (FRGS) with reference no FRGS/1/2018/TK0 4/UiTM/02/35 and Universiti Teknologi MARA (UiTM) Cawangan Pulau Pinang with filing no 600-IRMI/FRGS 5/3 (156/2019). The financial support is gratefully appreciated.

\section{REFERENCES}

[1] A. A. Malik, S. M. Maharum, M. Z. W. Mohd.Tohid, M. K. Rahmat, I. H. Hamzah, "Statistical analysis using taguchi method for wind turbine in ducting system," Indonesian Journal of Electrical Engineering and Computer Science, vol. 15, no. 1, pp. 26 33, 2019.

[2] A. A. Malik, S. M. M. Maharum, M. Z. W. M. Tohid, Z. Muhammad, I. H. Hamzah, Z. A. Halim, M. K. Rahmat, N. F. Haris, and Z. I. Rizman, "Development for the stand of solar photovoltaic based on the direction and angle analysis at North Peninsular Malaysia," Journal of Fundamental and Applied Sciences, vol. 10, no. 6S, pp. 934-948, 2018.

[3] A. A. Malik, S. M. M. Maharum, M. Z. W. Mohd Tohid, I. H. Hamzah, M. K. Rahmat, N. F. Haris, M. L. Mansor, M. H. Che Hasni, and Z. I. Rizman, "Analysis on the performance of 500w wind turbine in ducting System." Journal of Fundamental and Applied Sciences, vol. 10, no. 6S, pp. 1829-1843, 2018.

[4] Balat, M., and H. Balat, "Biogas as a renewable energy source - a review." Energy Sources, part A 31.14, pp. 1280-1293, 2009.

[5] Cheng, Jay, 2nd Edition. Biomass to renewable energy processes. CRC press, 2017.

[6] H. H. Goh, S. W. Lee, Q. S. Chua, K. C. Goh, and K. T. K. Teo, "Wind energy assessment considering wind speed correlation in Malaysia," Renew. Sustain. Energy Rev., vol. 54, pp. 1389-1400, 2016.

[7] Kumar, Rakesh \& Raahemifar, Kaamran \& Fung, Alan S., "A critical review of vertical axis wind turbines for urban applications," Renewable and Sustainable Energy Reviews, Elsevier, vol. 89(C), pp. 281-291, 2018.

[8] Hashim, Haslenda, and Wai Shin Ho. "Renewable energy policies and initiatives for a sustainable energy future in Malaysia." Renewable and Sustainable Energy Reviews, vol. 15, no. 9, pp. 4780-4787, 2011.

[9] A.R.N. Razliana, Y.M. Irwan, M. Irwanto, and Z. Farhana, "Generation of Wind Power In Perlis, Northern Malaysia," Proc. 2012 IEEE Symposium on Computers \& Informatics, 2012.

[10] M. Ahmadian, J. Ghorbanian, S. Shams, F. Goodarzvand, and J. Selvaraj, "Kuala Terengganu, Malaysia Wind Energy Assessment," Proc. 2013 IEEE Clean Energy and Technology (CEAT), Langkawi, pp. 214-219, 2013.

[11] A. Bennouk, A. Nejmi, M. Ramzi, "Performance and FMECA of a wind turbine based on SCADA and lidar data," International Journal of Applied Power Engineering (IJAPE), vol.8, no.2, pp. 101-109, 2019.

[12] Mahmoud M. El-Sharkawy, Mahmoud A. Attia, Almoataz Y. Abdelaziz, "Enhancement of power system performance with wind farm disturbances," International Journal of Applied Power Engineering (IJAPE), vol.8, no.1, pp. 159-172, 2019.

[13] N. Apergis, M. Ben Jebli, and S. Ben Youssef, "Does renewable energy consumption and health expenditures decrease carbon dioxide emissions? Evidence for sub-Saharan Africa countries," Renew. Energy, vol. 127, pp. 1011-1016, 2018.

[14] Chin E. Lin, Bao Chau Phan and Jia-Shian Chuang, "Small wind generation using complex airfoil turbine," Journal Cogent Engineering, vol. 6, no. 1, 2019.

[15] C. Wei Zheng, Z. Niu Xiao, Y. Hua Peng, C. Yin Li, and Z. Bo Du, "Rezoning global offshore wind energy resources," Renew. Energy, vol. 129, pp. 1-11, 2018.

[16] Sahishnu R.Shah, Rakesh Kumar, Kaamran Raahemifar, and Alan S.Fung, "Design, modeling and economic performance of a vertical axis wind turbine," EnergyReports, vol. 4, pp. 619-623, 2018.

[17] Kreider, Jan F. Handbook of heating, ventilation, and air conditioning. CRC Press, 2000.

[18] M. Dubey, S. Sharma, S, and R. Saxena, "Solar PV stand-alone water pumping system employing PMSM drive." Proc. 2014 IEEE Electrical, Electronics and Computer Science (SCEECS), pp. 1-6, 2014.

[19] Toja-Silva, Francisco, Antonio Colmenar-Santos, and Manuel Castro-Gil, "Urban wind energy exploitation systems: Behaviour under multidirectional flow conditions-opportunities and challenges." Renewable and Sustainable Energy Reviews, vol. 24, pp. 364-378, 2013.

[20] S. Mekhilef, and D. Chandrasegaran, "Assessment of off-shore wind farms in Malaysia," IEEE 2011 TENCON Conference, 2011.

[21] S. Ozdemir and G. Sahin, "Multi-criteria decision-making in the location selection for a solar PV power plant using AHP," Meas. J. Int. Meas. Confed., vol. 129, pp. 218-226, 2018. 
[22] S. B. Qamar and I. Janajreh, "Numerical investigation of solidity for cambered Darrieus VAWTs: Analysis of chord length," Proc. 2016 Int. Renew. Sustain. Energy Conf. (IRSEC 2016), vol. 42, no. 30, pp. 901-905, 2017.

[23] Xiaoli Tang, Xianghong Wang, Robert Cattley, Fengshou Gu, and Andrew D. Ball, "Energy Harvesting Technologies for Achieving Self-Powered Wireless Sensor Networks in Machine Condition Monitoring: A Review," Sensors (Basel). vol. 18, no. 12, pp. 4113-4152, 2018.

[24] W.Z. Leow, Y.M. Irwan, M. Irwanto, A.R. Amelia and I. Safwati, "Influence of wind speed on the performance of photovoltaic panel," Indonesian Journal of Electrical Engineering and Computer Science, vol. 15, no. 1, pp. 60-68, 2019.

[25] S. Chatinderpal, "Variable Speed Wind Turbine," International Journal of Engineering Science and Advanced Technology, vol. 2, no. 3, pp. 652-656, 2012.

\section{BIOGRAPHIES OF AUTHORS}
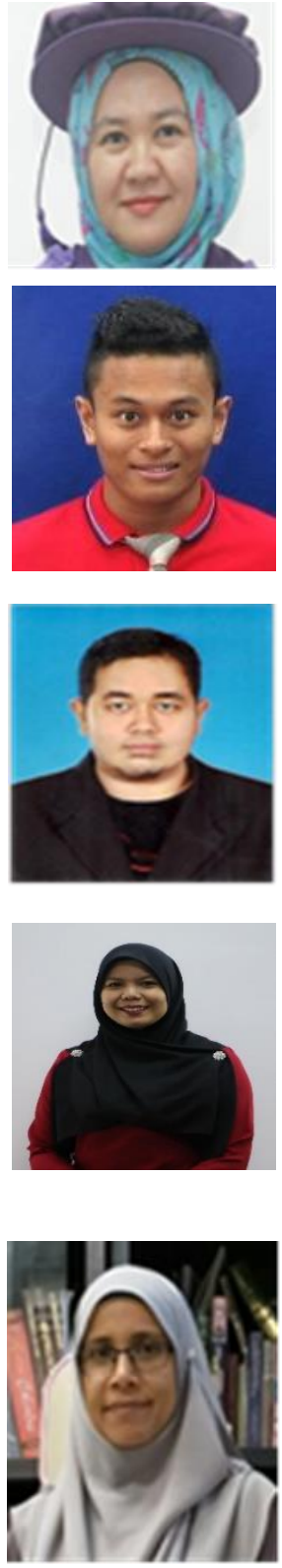

Irni Hamiza Hamzah was born in Machang, Kelantan on 6th December 1974. She obtained her B. Eng (Hons) in Electrical and Electronic Engineering in 1998, MSc. Electronics System and Design Engineering in 2005 and PhD in BioMEMs Sensors in 2013, which all had been obtained from School of of Electrical and Electronic Engineering, Universiti Sains Malaysia, Malaysia. She is currently a Senior Lecturer in Electronic Engineering Department, Faculty of Electrical Engineering, Universiti Teknologi MARA, Penang Branch Campus, Malaysia. Her research interests include Biosensors, BioMEMs, Neural Networks and Renewable Energy. She is a registered Board of Engineers Malaysia (BEM) Professional Engineer.

Muhammad Hazme Bin Roslan was born in Bukit Mertajam, Pulau Pinang on 26th April 1995. He obtained his Diploma in Electrical Engineering (Electronic) at UiTM Pasir Gudang, Johor in 2015. He graduated from UiTM Pulau Pinang in August 2019 majoring B. Eng (Hons) in Electrical and Electronic Engineering for the specialization in Power Engineering discipline. His Final Year Project focused on the development vertical axis wind turbine off-grid using power monitoring in heat ventilation air conditioning ducting system and analysis on the output current, temperature and air velocity from vertical axis wind turbine in HVAC ducting system environment. His current research interests include power system, power quality analysis, hardware troubleshooting and debugging.

Azman Ab Malik Azman Ab Malik was born in Melaka on 12 October 2018. He obtained his Diploma in Electronic Technology from KKTM Pasir Mas in 2007, Bachelor in Electrical Engineering and Technology from UNIKL BMI, Master in Electrical and Electronic Engineering from USM and Phd in Electrical Engineering from UITM. His interest in innovation towards electrical and electronic and cross multi-disciplinary area to identify a new model or method in engineering. His research interest include electrical power, power system, renewable energy, hybrid system, embedded system, wireless power transfer and energy storage. He is currently a Senior Lecturer in School of Engineering, Penang Skill Development Centre, Pulau Pinang, Malaysia.

NURUL WAHIDA BINTI M SAAD@MD SAAD has been involved in teaching and training for more than 4 years in Penang Skills Development Centre (PSDC). Academically, she holds a Master of Science Communication Engineering and Bachelor of Engineering (Hons) (Communication) from International Islamic University Malaysia. After graduation, she joined the education world and gained experience in teaching and training especially in Electronic, Signal and Systems, Digital Electronics and Digital Signal Processing. She is currently pursuing her study at Doctorate level in Electrical Engineering at University Technology Mara (UiTM). Her research interest includes wireless power, renewable energy, wave propagation and wireless communications.

Alhan Farhanah Abd Rahim obtained her B.Eng Hons in Electronics Engineering from University of Southampton in 1998, MSc and PhD in Solid State Physics from Universiti Sains Malaysia in 2003 and 2014 respectively. She is currently senior lecturer at the Faculty of Electrical Engineering, Universiti Teknologi MARA, Malaysia. Her research interests are in synthesizing and fabricating advance semiconductor materials (group IV, III-V)) and devices utilizing low cost techniques. Her PhD research work entittle: Studies of Ge nanostructures Studies of Si and Ge Nanostructures Synthesized By Electrochemical and Plasma Assisted Techniques For Sensing Applications. She is author and co-author of over 20 scientific publications in this field. She is a companion member of Institute of Engineer's Malaysia (IEM) and a registered Board of Engineers Malaysia (BEM) Professional Engineer. 